\title{
Data Considerations when Teaming with Avocational Detectorists
}

\section{Christopher T. Espenshade}

One highly effective means of public outreach is to have avocational detectorists assist in professional archaeological research (Figure 1). The National Park Service has a long history of involving avocational detectorists in battlefield research (Carlson-Drexler et al. 2008; Fox and Scott 1991; Parsons 2011; Scott and Fox 1987; Scott et al. 1989; Scott et al. 2008), and many professionals include such volunteers when pursuing research under American Battlefield Protection Program (ABPP) grants (e.g., McBride et al. 2013). The inclusion of this segment of the public allows the volunteers to understand archaeological methods and the importance of context, creates strong advocates for the preservation and interpretation of local battlefields, and provides extra labor to augment limited grant funds (Espenshade and Severts 2016). However, the incorporation of avocational detectorists may introduce data issues, including highly variable find rates; biases against certain classes of metal; and changes in intensity of detecting in relation to expectations of productive versus nonproductive areas.

In this article, the term "archaeologist" is used to denote professional archaeologists. In this context, "professional" denotes those who do this to earn a living, and those who abide by the ethical standards of the archaeological community. This does not mean that only archaeologists can be "professional" in their detecting skills or commitments to preservation. Likewise, "avocationalist" or "avocational detectorist" is used simply to indicate that these volunteers undertake detecting as a hobby or outside interest, not as their career. The term "volunteer" is used synonymously with "avocationalist," even though on many projects the professional archaeologists end up volunteering many hours.

\section{ABSTRACT}

As professional archaeologists and avocational detectorists increasingly collaborate in field research, professional archaeologists must consider how the use of avocational detectorists may bias data. The potential biases may include the following: highly diverse discovery rates; underrepresentation of certain classes of artifacts, especially ferrous items; work rates less than those of professional archaeologists; and amplified areas of negative data due to a self-fulfilling prophecy. Archaeologists are encouraged to collect the information needed to help recognize such biases and to regiment data collection to minimize biases.

Dado que los arqueólogos profesionales y los detectoristas no profesionales colaboran cada vez más en la investigación de campo, los arqueólogos deben tener en cuenta las maneras en que se pueden sesgar los datos de buscadores de no profesionales. Los sesgos potenciales pueden incluir los siguientes asuntos: muy diversas tasas de descubrimiento; sub-representación de ciertas clases de artefactos, especialmente artículos ferrosos; ritmos de trabajo inferiores a las de los arqueólogos profesionales; y amplificación de las áreas de datos negativos debido a profecías autocumplidas. Se recomienda a los arqueólogos que recojan la información necesaria para ayudar a reconocer estos sesgos, y que establezcan procedimientos de recopilación de datos para minimizar los sesgos. 


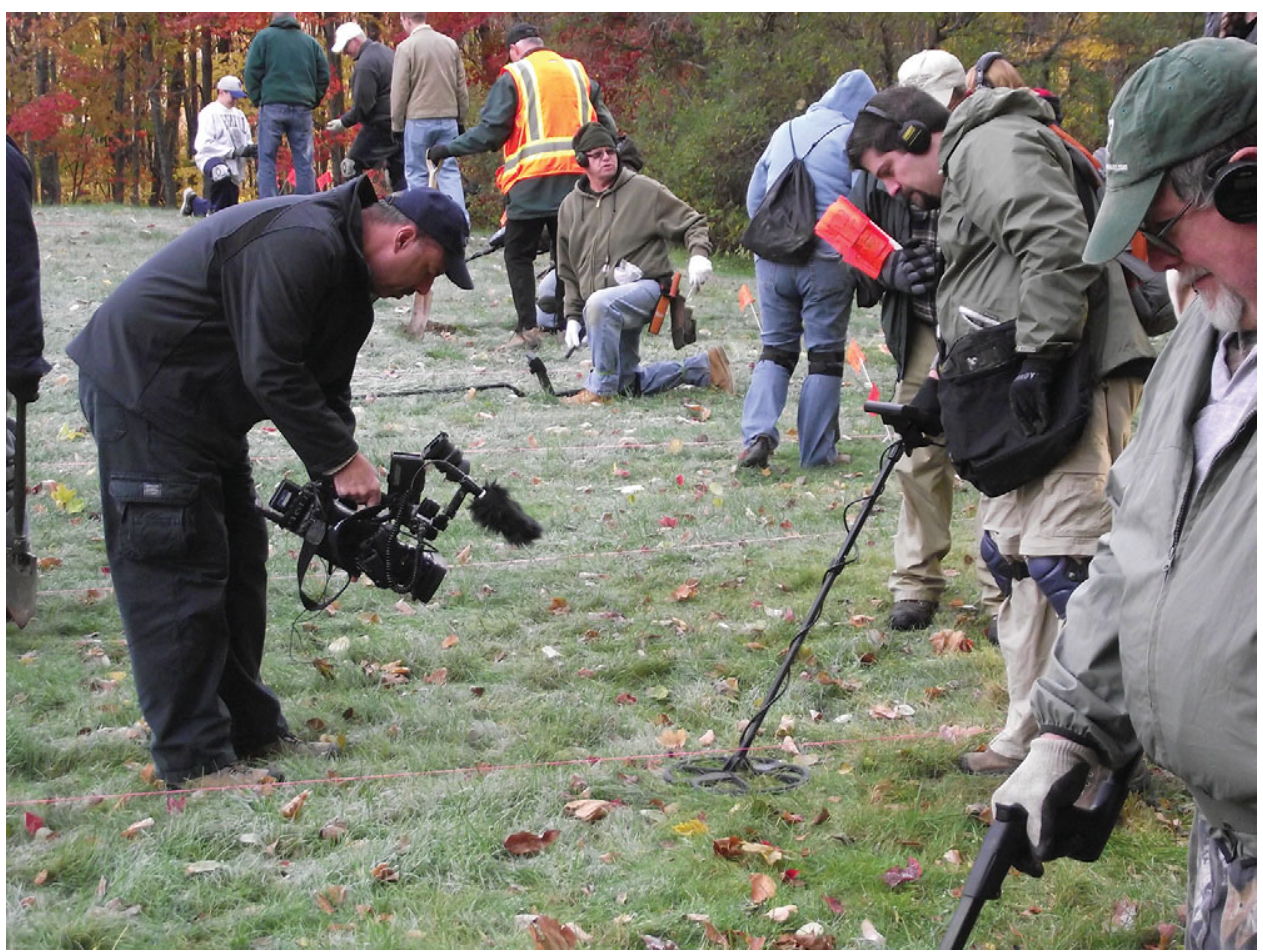

FIGURE 1. Avocational detectorists beginning their survey lanes at Bennington Battlefield (photograph by the author).

Labels can get in the way of building collaborations, and the archaeologist's goal should be to not offend anybody.

\section{POTENTIAL PROBLEMS AND SOLUTIONS}

Including volunteers in battlefield field research (or research at any historical archaeology site) means that archaeologists must consider the possible limitations of the derived data. Avocational detecting, even under the supervision of professional archaeologists, may yield data that will differ from data recovered by archaeologists trained in detecting. Although any archaeological research must deal with the varying performances of individual contributors, the problem is often exacerbated with avocational detectorists because the professional archaeologist may have little prior knowledge of the abilities of the volunteers. As the efficacy of detecting is generally difficult to gauge, archaeologists need to adjust their data expectations and research designs accordingly. This is a relatively new issue, as the use of avocational detectorists in professional research has only recently gained widespread acceptance in the discipline (for more on the relationship of avocational detectorists and professional archaeologists, please see Reeves [2015] and the recent report of the Society for American Archaeology's Professional Archaeologists, Avocational Archaeologists, and Responsible Artifact Collectors Relationships Task Force)

\section{Find Rates}

Much of archaeological inference draws on an assumption of consistent rates of recovery. If we have a crew shovel testing, if they are all excavating holes of similar volume, and if they are all screening their dirt through the same size mesh, we can take the results from the sample as being representative of the sampled universe. Metal detecting is different, however, because devices vary in how well they work in specific conditions, and because volunteers and archaeologists offer diverse personal experience. Factors that may affect productivity may include experience, work ethic, device, soil conditions, weather, and fatigue. When considering productivity, we must also recognize that archaeologists are being paid and should feel an obligation to put in a hard eight hours of work each day. Avocationalists are volunteering a weekend day, are enjoying themselves, are interacting with their peers, and cannot be held to the same work ethic. Differences in recovery rates can reflect effort, not necessarily skill. Although some studies have suggested that the find rate is related to years of experience (Jolley 2007), others have demonstrated a lack of correlation between those two attributes (Wood 2010).

You can never know the nature and true intensity of training and experience of avocationalists and archaeologists, and we must acknowledge that productivity will vary, even if the artifact density is fairly constant (indeed, the performance of a single detector may vary with fatigue, attitude, weather, and other factors).

During the recent ABPP research at Bennington Battlefield of the Revolutionary War, Commonwealth Heritage Group (CHG) made an effort to compare the metal detecting performances of volunteers and archaeologists. Two of the latter had received continuing education training in Advanced Metal Detecting for the Archaeologist (AMDA). This class is certified by the Register of Professional Archaeologists and is designed to teach best practices in applying detecting in professional research (Espenshade and Silliman 2016). The author (the third archaeologist) is 


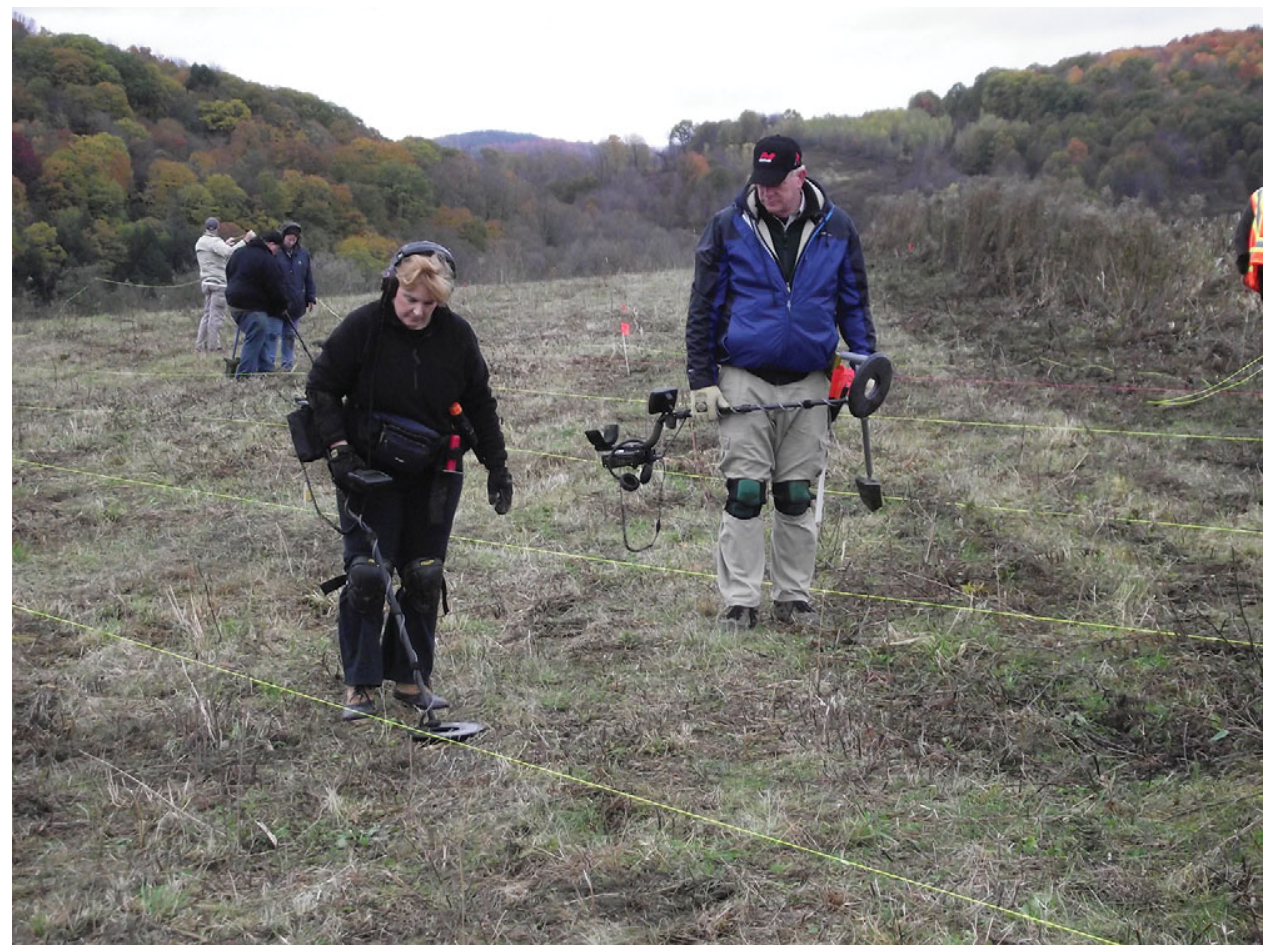

FIGURE 2. Survey lanes help assure controlled coverage, Bennington Battlefield (photograph by the author).

a cofounder and an instructor for AMDA. During two weeks of field research, CHG designated four weekend days when avocational detectorists could assist in the research on state-owned portions of the battlefield. We required preregistration and limited an individual to participating on only one of the four days. Fifty-four avocational detectorists participated, with some driving more than four hours, one way, to attend. The goal was to have no more than four avocationalist detectorists per professional archaeologist. The following discussion is drawn from our report on the Bennington research (Selig et al. 2016).

The research design for the Bennington Battlefield called for metal detector survey to evaluate the suspected locations of key battle events. These locations had been determined through a review of the archival record, historic maps, and military terrain analysis. The archaeological finds-in conjunction with the other data classes-were then used to revise the battle narrative and to guide the creation of an interpretive plan for the battlefield.

For the present project, three measures of efficacy were considered. The first measure is simply whether the effort yielded useful data for the interpretation of the site. At Bennington, the volunteers successfully recovered 200 battle-related metal detector finds and provided data valuable for refining the nature of actions in different areas of the battlefield. At the German Redoubt, the volunteer efforts helped define both the former position of the redoubt and the former wood line (Figure 2). Their artifact recovery also suggested that the field piece at the German Redoubt fired only one round (possibly two) of canisters before the redoubt was overrun. At the Tory Redoubt, the volunteer data helped confirm the location of the redoubt and helped verify that the onslaught was focused on the Tory right (Figure 3). So, impor- tantly, the volunteers were successful in capturing data valuable to interpreting the battlefield. For those archaeologists stubborn about including volunteers, this level of efficiency should be all that is necessary to change minds. On top all the other benefits of public engagement, the inclusion of volunteers yielded important data on the battlefield resource.

On a second level, the discovery rate of the volunteers can also be compared against that of the archaeologists. The professional archaeologists expended 22.5 person days in metal detecting and discovered 197 battle-related finds (8.8 artifacts/person day). The volunteers expended 54 person days metal detecting and recovered 200 battle-related finds (3.7 artifacts/person day). In summary, the archaeologists discovered metal detector finds at more than twice the rate of the volunteers. The higher find rate by the archaeologists occurred despite the fact that the volunteers were purposefully placed on the areas of the battlefield with the highest density of artifacts, but the archaeologists expended part of their effort in minimally productive or unproductive areas (in terms of artifact recovery; the negative data were still important). It is acknowledged that the archaeologists were selected for this project due to their strong skills; their performance does not reflect the expectation for any random archaeologist handed a detector. It is further acknowledged that these data compare group performance, and that the author noted disparate skills within the detector corps.

It is important to acknowledge that there was not one, consistent detector used by all the archaeologists and avocationalists. The archaeologists used a Fisher Labs Gold Bug Pro with double-D coil, a Minelab E-trac, and an XP Deus 3.2. Not all of the avocationalists identified the brand and model of their detector, 


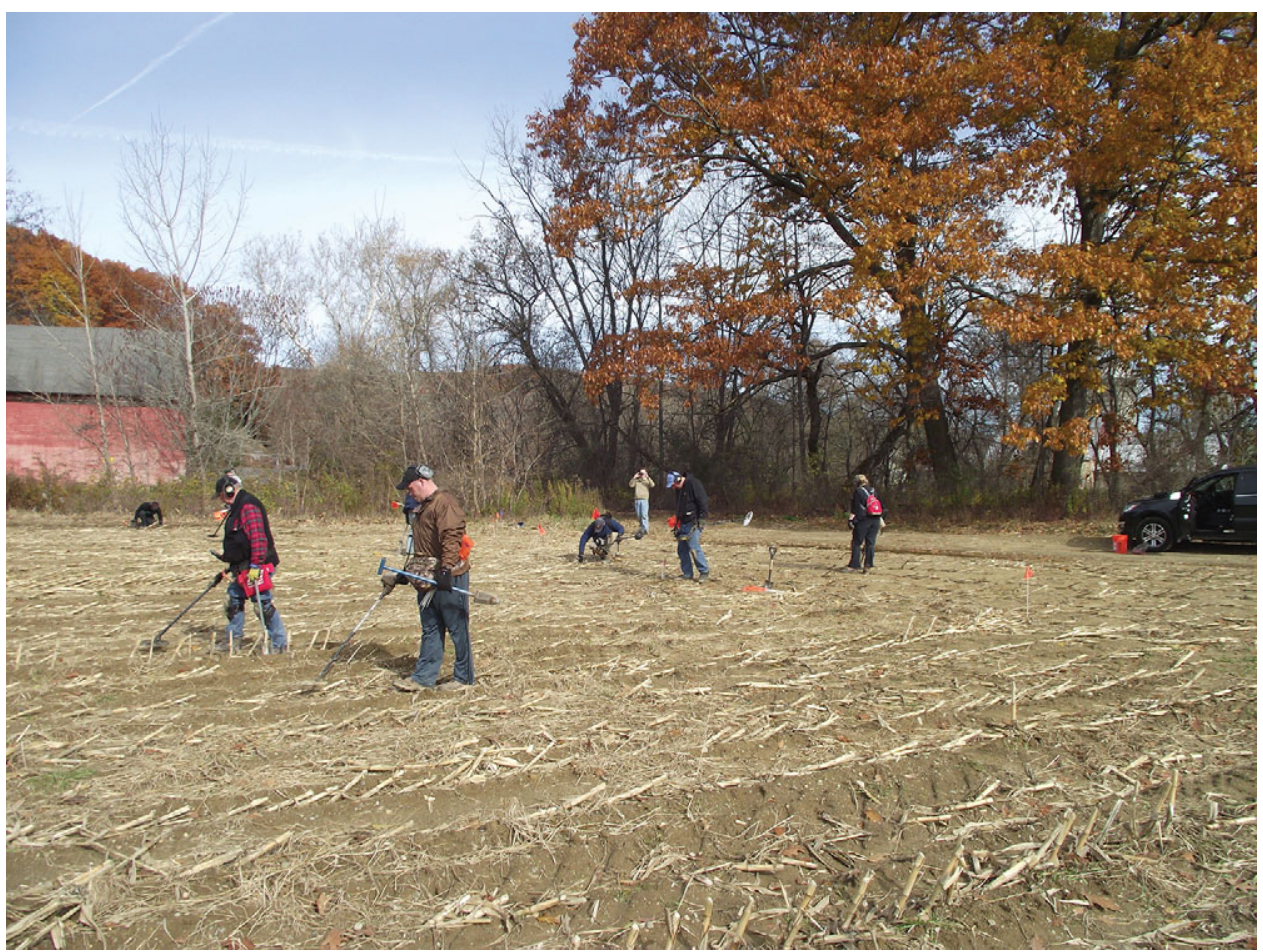

FIGURE 3. Volunteers using corn rows to assure full coverage, Bennington Battlefield (photograph by the author).

but the partial record includes the following: Fisher Labs Gold Bug Pro Garrett AT-Pro $(n=14)$; Minelab E-trac $(n=2)$; Minelab CTX $(n=1)$; Minelab, model unspecified $(n=3)$; Teknetics T2 $(n=2)$; Teknetics G2 $(n=1)$; Tesora Tejon $(n=1)$; Whites V31 $(n=2)$; Whites Coinmaster GT $(n=2)$; Whites MXT Pro $(n=2)$; Whites XLT $(n=2)$; Whites M6 $(n=3)$; Whites DFX $(n=3)$; and XP Deus $3.2(n=4)$. The efficacy of a device will vary with how well it matches (through factory settings and capabilities) or is adjusted to compensate for on-site soil conditions and artifact types. Both the avocationalists and the archaeologists used pin-pointers in target excavation.

As a third level of measurement, you can compare find rates for archaeologists and avocational detectorists in a small area of a site. At Bennington, the author spent an hour on October 30 detecting a single transect in the previously unsurveyed portion of the grass field north of the German Redoubt; he discovered two balls (i.e., 2.0 artifacts/hour). On October 31, when eight volunteers spent two hours each on transects immediately adjacent to the author's transect, they recovered six balls (i.e., .375 artifacts/hour).

It must be kept in mind that the goal at Bennington was not to recover every artifact in a survey area but to characterize the scatters. Full recovery is both unreasonable and unnecessary, especially on unthreatened sites. Both experimental data (e.g., Heckman 2005) and archaeological results (e.g., Espenshade 2014) demonstrate that even repeated detecting of many years does not completely deplete artifacts from a battlefield. The volunteers provided valuable data with the finds they made, and their feedback suggests that this was a very positive form of pub- lic outreach. We hoped to use the volunteer effort to broaden archaeological knowledge of the battlefield. Lastly, we hoped that exposing the avocationalists to professional research methods might create teaching opportunities, especially with regard to recording proveniences and bagging/labeling finds. Overall, the volunteer efforts were highly successful.

In terms of solutions to variability in find rates, there are a number of potential solutions:

(1) Monitor the issue. Unless you are measuring the differences in find rates, you will never know whether the problem is significant for your analyses and inferences.

(2) Include archaeologists among your detecting corps. There is no single, universal recovery rate, and researchers need to establish a baseline from which to measure variability. Such data are also instructive from the obverse perspective. It is difficult to know how well professional archaeologists are detecting. By having the avocationalists as a control group, a reviewer can be confident about the efficacy of the professional detectorists if the discovery rates of the professionals match or exceed those of the volunteers.

(3) Regiment data collection. When you have individuals of divergent skills and experience, it is imperative to maximize spatial control of the data collection efforts. When feasible, create string-demarcated survey lanes (each one-swing wide) to regiment coverage. All find locations should be mapped with either a total station or a GPS unit. Other means of regimenting data collection include establishment of grid squares, or the use of dog-leash circles. 
(4) Move perpendicularly across zones of interest. Even if certain individuals have a lower find rate than others, you can still recognize patterns if everybody is moving perpendicular to suspected boundaries, rather than parallel. So, for example, at Bennington we laid out collection lanes northwest to southeast, running perpendicular to the suspected tree line. Following this approach, we could see consistency in the distribution of finds by each individual, as well as by the overall group. We then had greater confidence that areas of no or low artifact recovery were reflecting reality rather than the lesser skill of one individual.

(5) Avoid overreliance on density-based inferences. To return to the shovel testing analogy, you would not put great confidence in a data set if the mesh size varied from .25 to 2.0 inches, and if the volume of shovel tests varied wildly. Metal detecting-whether performed by archaeologists, volunteers, or a mixture-is highly variable. Archaeologists must keep these limitations in mind.

\section{Bias Against Iron}

Many avocationalists (especially in the eastern United States) have trained themselves to ignore ferrous signals. They do not want to waste their detecting time digging nails, horseshoes, or farm implements. It can be difficult for these individuals to readjust, even when they are told of the possible presence of important ferrous artifacts such as canister shot. We may be asking too much when we expect an avocationalist to reverse 15-20 years of past practice. When we look at assemblages derived from avocational detecting, the archaeologist must be aware of a strong potential of bias against ferrous artifacts. The recovered assemblage may present an inaccurate view of the actual sampling universe. Possible solutions to the iron bias issue include:

(1) Educate your volunteers on the importance of iron artifacts to your analyses.

(2) Tell volunteers about the types of important iron artifacts that are expected from a site. At Bennington, for example, we knew that the distribution of canister shot would be important in reconstructing certain battle actions. By telling the volunteers this from the start, we saw fairly good compliance with our request to locate and excavate ferrous targets.

(3) Emphasize that speed is not a concern. Many detectorists see the digging or iron artifacts as a waste of time. If archaeologists de-emphasize the speed/time concerns, detectorists are more likely to excavate iron objects. This may need to be reinforced in the field (e.g., "Remember, this is not a race. This is not about who finishes first.")

(4) Applaud those who recover iron artifacts. As you are trying to change entrenched behaviors, positive reinforcement may be necessary and effective. When Volunteer Joe sees Volunteer Jane receiving praise for her iron discovery, Joe may stop bypassing ferrous objects.

(5) Informally monitor field behavior. The archaeologist needs to pay attention to what classes of artifacts are being found by volunteers and archaeologists.

(6) If volunteers seem to be avoiding iron objects, and if time permits, resurvey key areas focusing on iron signals. If volunteers know they may have to go over an area again to recover the iron they skipped (intentionally or inadvertently), they may become more thorough on their initial pass.
(7) Be mindful of the potential bias when characterizing the assemblage. As with density/distribution, archaeologists must be aware that iron objects may be underrepresented in the collection. We must avoid arguments and inferences that rely heavily on the paucity or absence of iron artifacts.

(8) Have the detectorists work in pairs. The level of compliance with the mandate to dig all targets increases when there are two people working together.

\section{Poor Areas and the Risk of a Self-fulfilling Prophecy}

Interpretations of battlefields and delineation of other historic sites rely heavily on the comparison of productive areas and areas of little artifact recovery. Professional archaeologists must be aware that some of those observed differences may be the result of a self-fulfilling prophecy, whereby detectorists work faster or less thoroughly in areas perceived as poor, compared to areas perceived as productive. When avocationalists are detecting on their own, they will often leave an area where they are not finding material. Even archaeological technicians, who should know better, must be reminded to be equally thorough in all areas, whether or not finds are forthcoming. Potential solutions to this issue include:

(1) Explain the importance of negative data. Archaeologists need to explain why we need to delineate areas lacking artifacts, and why that verification needs to be thorough. If possible, explain that blank spaces may be of importance in interpreting the site at hand.

(2) Acknowledge that archaeologists struggle with this problem. This is not exclusively a volunteer issue; it is a human behavior issue. Rather than lecturing volunteers on their faults, acknowledge that everybody has a tendency to work faster through areas perceived as poor.

(3) As feasible, assure collecting lanes crosscut areas of good artifact return. People will tolerate areas of poor or mediocre returns if they are certain that their collection area will also include areas of good return. Archaeologists need to regiment search areas such that everybody gets a mixture of bad and good.

(4) Reinforce thoroughness over the entire collection area.

(5) Monitor the performances in the field.

(6) When considering the data, be aware that the self-fulfilling prophecy will often lead to an overemphasis or misleading clarity of the boundary between areas of high and low artifact return.

Education of the avocationalists is a common theme among the solutions suggested. This education must continue beyond the completion of the field work. The lessons will be brought home when volunteers are shown the final product, the analysis, and reporting. All volunteers should be provided a copy of the final report. In certain cases, this will need to be a redacted version, to comply with mandates of not sharing sensitive site information (the irony is recognized, in that all the volunteers know where the sites are because they assisted in the field work). Where redaction is required, mapping can be provided without geographic reference points, such as was done for Figures 4 and 5 of this article. Beyond showing basic decency and respect to 


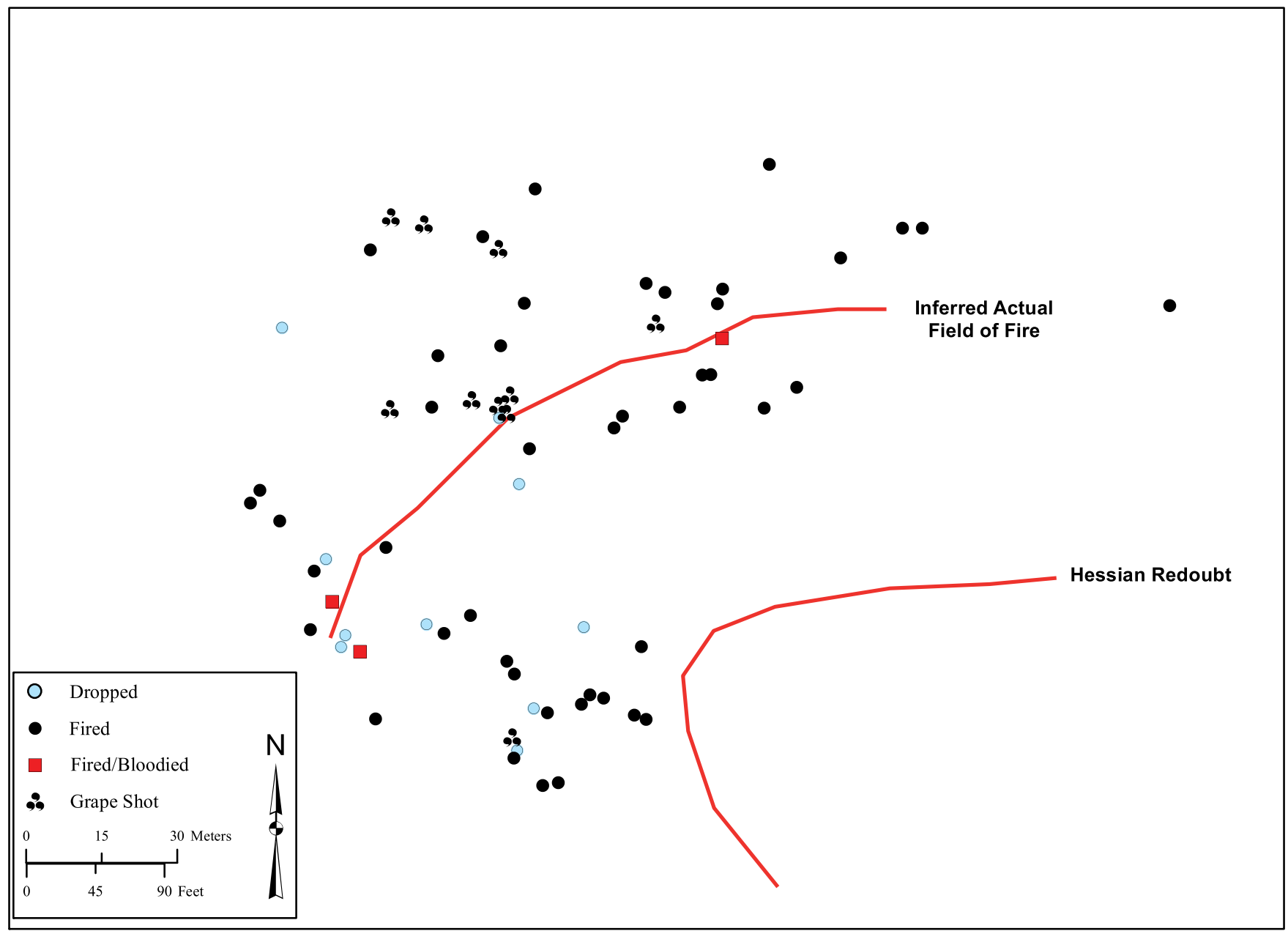

FIGURE 4. Metal detector finds at the German (or Hessian) Redoubt, Bennington Battlefield.

your collaborators, the sharing of the report will strongly reinforce methodological messages offered in the field. The data issues should diminish as avocational detectorists gain experience working with archaeologists, and it will be productive to use repeat volunteers when feasible.

\section{CONCLUSIONS}

It is acknowledged that all the potential issues that derive from using volunteers are also present, to some degree, when using only a crew of professional archaeologists. The main difference is that volunteer days often see a large number of volunteers participating, and the supervising archaeologist often has no prior experience with these individuals. The purpose of this paper is not to disparage volunteers; instead, this paper is intended to identify potential data limitations and to suggest possible means of reducing those biases.

Perhaps in an ideal world, data consistency would benefit from using only individuals with a tested, identical high-skill level, swinging devices of identical efficacy. However, that would not be ideal in terms of embracing the contributions of public volunteers. Although the robustness of the data may suffer slightly, the involvement of avocationalists creates a segment of the public that is invested in the research and preservation of the resource. The inclusion of avocationalists provides archaeologists an opportunity to educate volunteers on archaeological methods and the related emphasis on context, and may allow archaeologists to change best practices of the volunteers as they return to their hobby. Inclusion also allows the volunteers to provide valuable skills and data for the interpretation of resources.

As a corollary to the suggested solutions, it is imperative that archaeologists learn best practices in metal detecting, and learn detecting skills themselves. Metal detecting is a highly useful method of site discovery, delineation, evaluation, and interpretation on a wide variety of contact period and historic sites. Professional archaeologists have an ethical obligation to learn detecting skills. The possible availability of proxies (i.e., avocational detectorists) does not excuse an archaeologist from expanding their methodological toolbox. Archaeologists cannot properly supervise volunteers if the archaeologists do not know best practices in metal detecting.

Archaeologists are increasingly collaborating with avocational detectorists, with much success. At Bennington, for example, the involvement of volunteers provided valuable information for 


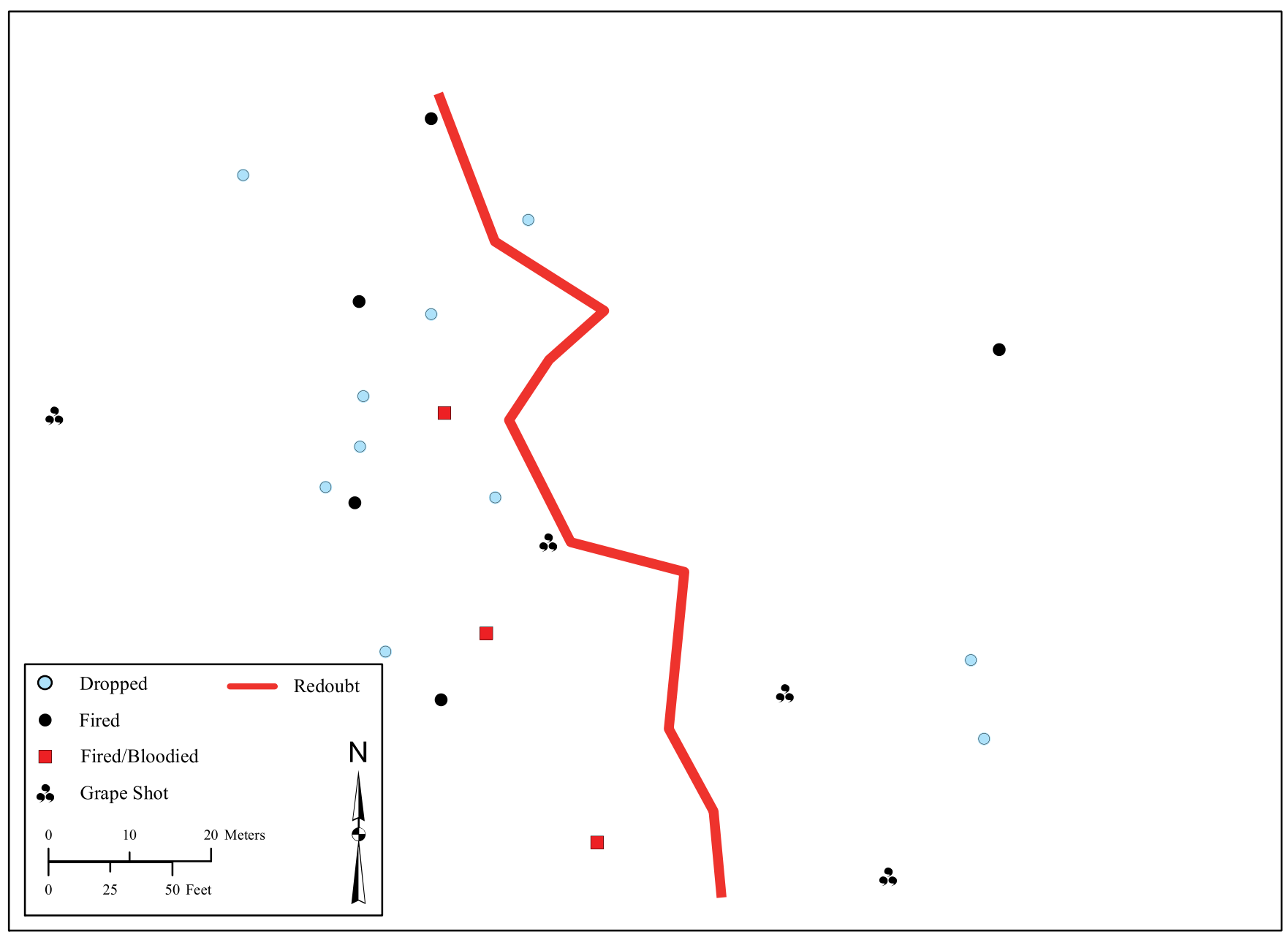

FIGURE 5. Metal detector finds at the Tory Redoubt, Bennington Battlefield.

the interpretation of key areas of the landscape, created a corps of citizens vested in the preservation and presentation of the battlefield, and educated many avocationalists in how and why archaeological research is conducted. The many positives of such collaboration come with a potential for certain limitations in the resultant data. These limitations are identifiable and can be mitigated through awareness in the field and during analysis. Great information can be gained through collaboration, but archaeologists must remain aware of potential biases when they implement their research designs and analyses.

\section{Acknowledgments}

The work at Bennington Battlefield was completed under an ABPP grant (GA-2287-14-013) to the NY Parks. This material is based on work assisted by a grant from the Department of the Interior, National Park Service. Any opinions, findings, and conclusions or recommendations expressed in this material are those of the author(s) and do not necessarily reflect the views of the Department of the Interior. Both the ABPP and NY Parks are to be commended for their willingness to embrace public outreach through field collaboration. I thank the many volunteers who participated at Bennington. Their efforts were vital in the interpretation of the battlefield, and I greatly enjoyed working with them. Mark Ludlow and Kevin Bradley were my fellow archaeologists in the field, and their expertise is evident in the find rates. The work at Bennington was completed when I was employed at Commonwealth Heritage Group, and the writing of this paper was supported by my present employer, Skelly and Loy, Inc. The perspectives offered in this paper have been heavily influenced by interaction with my fellow instructors and students of AMDA. $A$ redacted version of the Bennington Battlefield study will be available from ABPP in 2017. I thank Dr. Matthew Reeves (peer reviewer), and two anonymous peer reviewers for the recommended improvements to the draft.

\section{Data Availability Statement}

The data referenced in this article is available from the Bennington Battlefield project curation package, curated in late 2016 at the New York State Office of Parks, Recreation, and Historic Preservation, 625 Broadway, 2nd Floor, Albany, New York 12207. 


\section{REFERENCES CITED}

Carlson-Drexler, Carl G., Douglas D. Scott, and Harold Roeker 2008 "The Battle Raged . . . with Terrible Fury": Battlefield Archeology of Pea Ridge National Military Park. National Park Service, Midwest Archeological Center, Lincoln, Nebraska.

Espenshade, Christopher T.

2014 Addressing the Myths: Recent Studies at the Blountville, Tennessee, and Resaca, Georgia, Battlefields. In From These Honored Dead: Historical Archaeology of the American Civil War, edited by Clarence R. Geier, Douglas D. Scott, and Lawrence E. Babits, pp. 247-262. University of Florida Press, Gainesville.

Espenshade, Christopher T., and Patrick Severts

2016 Better Training = Better Battlefield Interpretation: The AMDA and APP Classes. In Preserving Fields of Conflict: Papers from the 2014 Fields of Conflict Conference and Preservation Workshop, edited by Steven D. Smith, pp. 11-16. South Carolina Institute of Archaeology and Anthropology, Columbia.

Espenshade, Christopher T., and Garrett Silliman

2016 Status Report, February 2016: Advanced Metal Detecting for the Archaeologist, an RPA-Certified, Continuing Professional Education Course. Electronic document, http://amda.modernheritage.net/ wp-content/uploads/2016/02/amdaSTATUS-REPORTfeb2016.pdf, accessed September 28, 2016.

Fox, Richard A., Jr., and Douglas D. Scott

1991 The Post-Civil War Battlefield Pattern: An Example from the Custer Battlefield. Historical Archaeology 25(2):92-103.

Heckman, Elsie

2005 Geophysical Methodologies and Test Site for Battlefield Archaeology Unpublished Master's thesis, Department of Anthropology, University of Arkansas, Fayetteville.

Jolley, Robert

2007 An Archaeological Survey of the Confederate Left Flank, Third Battle of Winchester, Virginia, September 19, 1864. Quarterly Bulletin of the Archeological Society of Virginia 62(4):190-229
McBride, Kevin, Douglas Currie, David Naumec, Ashely Bissonnette, Noah Fellman, Laurie Pasteryak, and Jacqueline Veninger

2013 Battle of Mistick Fort: Site Identification and Documentation Plan, Public Technical Report. Mashantucket Pequot Museum \& Research Center, Mashantucket, Connecticut.

Parsons, Timothy A.

2011 Archeological Investigations at Fort Heiman, Fort Donelson National Battlefield, Calloway County, Kentucky. National Park Service, Southeast Archeological Center, Tallahassee, Florida.

Reeves, Matthew

2015 Sleeping with the "Enemy": Metal Detecting Hobbyists and Archaeologists. Advances in Archaeological Practice 3(3):263-274.

Scott, Douglas D., and Richard A. Fox Jr.

1987 Archaeological Insights into the Custer Battle: An Assessment of the 1984 Field Season. University of Oklahoma Press, Norman.

Scott, Douglas D., Richard A. Fox Jr., Melissa A. Conner, and Dick Harmon 1989 Archaeological Perspective on the Battle of Little Big Horn. University of Oklahoma Press, Norman.

Scott, Douglas D., Harold Roeker, and Carl G. Carlson-Drexler

2008 "The Fire Upon Us Was Terrific": Battlefield Archeology of Wilson's Creek National Battlefield, Missouri. National Park Service, Midwest Archeological Center, Lincoln, Nebraska.

Selig, Robert, Christopher T. Espenshade, Wade Catts, Elizabeth LaVinge, and James Montney

2016 Historical and Archaeological Study of the Bennington Battlefield of the Revolutionary War (Draft Report). Commonwealth Heritage Group, Jackson, Michigan.

Wood, Alyson

2010 Understanding Variable Affecting Data Collected During Meta Detector Survey. Journal of Middle Atlantic Archaeology 26:75-80.

\section{AUTHOR INFORMATION}

Christopher T. Espenshade Skelly and Loy, Inc., 3280 William Penn Way, Pittsburgh, PA 15238, USA (cespenshade@skellyloy.com) 